\title{
Multiple classes and isoforms of the RNA polymerase recycling motor protein HelD
}

Joachim S. Larsen ${ }^{1}$ (ORCID: 0000-0001-7270-8081), Michael Miller ${ }^{1}$ (ORCID: 0000-0001-79903381), Aaron J. Oakley ${ }^{2}$ (ORCID: 0000-0002-4764-014X), Nicholas E. Dixon ${ }^{2}$ (0000-0002-59586945) and Peter J. Lewis ${ }^{1,2^{*}}$ (ORCID: 0000-0002-1992-062X)

${ }^{1}$ School of Environmental and Life Sciences, University of Newcastle, Callaghan, NSW 2308, Australia

${ }^{2}$ School of Chemistry and Molecular Bioscience, University of Wollongong and Illawarra Health and Medical Research Institute, Wollongong, NSW 2522, Australia

* To whom correspondence should be addressed. Tel: +612 4921 5701; Email:

Peter.Lewis@newcastle.edu.au, lewisp@uow.edu.au

KEY WORDS: RNA polymerase, gene expression regulation, helicases, phylogenetic analysis

\section{SUMMARY}

Efficient control of transcription is essential in all organisms. In bacteria, where DNA replication and transcription occur simultaneously, the replication machinery is at risk of colliding with highly abundant transcription complexes. This can be exacerbated by the fact that transcription complexes pause frequently. When pauses are long-lasting, the stalled complexes must be removed to prevent collisions with either another transcription complex or the replication machinery. HeID is a protein that represents a new class of ATP-dependent motor protein distantly related to helicases. It was first identified in the model Gram-positive bacterium Bacillus subtilis and is involved in removing and recycling stalled transcription complexes. To date, two classes of HelD have been identified: one in the low $G+C$ and the other in the high G+C Gram-positive bacteria. In this work we have undertaken the first comprehensive investigation of the phylogenetic diversity of HelD proteins. We show that genes in certain bacterial classes have been inherited by horizontal gene transfer, many organisms contain multiple expressed isoforms of HelD, some of which are associated with antibiotic resistance, and that there is a third class of HelD protein found in Gram-negative bacteria. Therefore, HelD proteins represent an important new class of transcription factor associated with genome maintenance and antibiotic resistance that are conserved across the Eubacterial kingdom. 
Running Title: Phylogeny of HelD

\section{INTRODUCTION}

Transcription elongation is punctuated by pauses that serve important functions in permitting correct folding of structural RNA, efficient coupling of transcription and translation and ensuring efficient transcription termination at the correct site (Saba et al., 2019). Whilst most pausing events serve an important function, on occasion RNA polymerase (RNAP) is unable to restart transcription and must be removed from the DNA to prevent damaging collisions with the DNA replication machinery or other transcription complexes (Adelman and Lis, 2012, Gupta et al., 2013, Pomerantz and O'Donnell, 2008, Pomerantz and O'Donnell, 2010, Rocha, 2004). Several systems used to resolve stalled transcription complexes have been characterised; for example, Mfd has been shown to bind to stalled transcription complexes (either a stochastic pause during transcription of structured RNA or at a site of DNA damage), physically removing it from the DNA or restarting it via a RecG-like ATPase motor domain (Ragheb et al., 2021, Ghodke et al., 2020, Ho et al., 2018, Shi et al., 2020, Westblade et al., 2010, Kang et al., 2021, Le et al., 2018). In B. subtilis RNaseJ1 clears stalled RNAP using a torpedo mechanism (5'-3' exonuclease activity followed by RNAP displacement) (Sikova et al., 2020), and in Escherichia coli the helicase protein RapA has been shown to be important in recycling RNAP (Liu et al., 2015). UvrD/PcrA in concert with Gre factors has been reported to act on RNAP stalled at a DNA lesion, binding to the complex and using the energy of ATP hydrolysis to backtrack away from the lesion to allow repair systems access to the damaged DNA (Epshtein et al., 2014, Hawkins et al., 2019), although it now appears that the role of these helicases is in preventing formation of, and resolving, R-loops (RNA-DNA hybrids) that can have a detrimental effect on DNA replication (Urrutia-Irazabal et al., 2021).

\section{An additional system identified in Gram-positive bacteria required for recycling stalled transcription} complexes involves the action of the motor protein HelD (Wiedermannova et al., 2014). The designation of HelD (also called helicase IV) was originally made for a protein identified in E. coli as a weakly processive 3'-5' DNA helicase (Wood and Matson, 1987). To avoid confusion with the separate classes of HelD proteins that are the focus of this work, the E. coli protein will be referred to as helicase IV. Based on conserved sequence motifs Helicase IV is a superfamily 1 (SF1) helicase, related to housekeeping helicase UvrD/PcrA (Figure 1). The B. subtilis gene $y v g S$ was assigned the name helD based on limited protein sequence conservation to helicase IV (Wiedermannova et al., 2014), although the proteins differed with respect to domain organisation (Koval et al., 2019, Wiedermannova et al., 2014)(Figure 1). Little functional, and no structural information is available for helicase IV, although a model generated by AlphaFold2 (Jumper et al., 2021) enables tentative comparison of UvrD/PcrA, helicase IV and B. subtilis HelD (Figure 1). Helicase IV and HelD show 
similarity with UvrD/PcrA around the well-defined 1A and 2A helicase domains (blue and orange, respectively, Figure 1A), but not in other structural motifs associated with helicase activity (UvrD/PcrA domains 1B and 2B). Both helicase IV and HelD have $\mathrm{N}$-terminal domains not present in UvrD/PcrA helicases, and helicase IV has a putative 1B domain which may account for its reported helicase activity, whilst in the equivalent 1B domain position HelD contains unrelated sequence that folds into a novel clamp-arm (CA) structure important in transcription recycling (Newing et al., 2020, Wiedermannova et al., 2014). Whilst UvrD/PcrA and helicase IV have helicase activity, HelD shows none suggesting it has evolved from an SF1-type helicase into a transcription recycling factor that utilises the energy from ATP hydrolysis catalysed by its helicase motifs for its transcription-related activity.

Studies on HelD from low $\mathrm{G}+\mathrm{C}$ (Bacillus subtilis) and high $\mathrm{G}+\mathrm{C}$ (Mycobacterium smegmatis) Grampositives revealed that there are two distinct classes of enzyme, confirmed by phylogenetic and structural analyses (Kouba et al., 2020, Newing et al., 2020, Pei et al., 2020). Class I HelD was described from B. subtilis, whilst the structurally distinct Class II enzyme was identified in $M$. smegmatis (Kouba et al., 2020, Newing et al., 2020, Pei et al., 2020). Class I and II HelDs have similar motor domains but differ in the structure of their arms and the mechanism by which these arms perform the mechanical activity of removing nucleic acids and recycling RNAP (Kouba et al., 2020, Newing et al., 2020, Pei et al., 2020).

\section{The recent structures of HelD from B. subtilis and M. smegmatis bound to core RNAP $\left(\alpha_{2} \beta \beta{ }^{\prime} \omega\right)$} (Kouba et al., 2020, Newing et al., 2020) are shown in Figure 2A and B, along with the Class I $B$. subtilis (Figure 2C) and Class II M. smegmatis (Figure 2D) enzymes. HelD has an unusual mode of action dependent on two arms (CA and SCA, Figure 2C and D) attached to the central UvrD-like ATPase motor domain (Head and Torso, Figure 2C and D), in which nucleic acids are pushed out of the active site whilst the DNA binding clamp and RNA exit channels are simultaneously opened, leading to the release of the stalled RNAP (Newing et al., 2020). This recycling activity is powered by ATP hydrolysis and the mechanical action of the two arms that flank the motor domain. In the Class I HelD, the long SCA (Figure 2A and C) is able to physically remove nucleic acids from the active site (dotted circle in Figure 2A), whereas in the Class II HelD the SCA is too short, and instead nucleic acid removal is performed by a CA insert called the PCh-loop (Figure 2B and D) (Kouba et al., 2020, Newing et al., 2020). Recent reports also suggest that some Class II HelDs (from M. abscessus and Streptomyces venezuelae) are able to confer rifampicin resistance through removal of rifampicin by the PCh-loop (Hurst-Hess et al., 2021, Surette et al., 2021). 
In this work, we take advantage of the recent structural information to compile a detailed phylogenetic analysis of HelD showing that many organisms contain more than one (up to 5) different versions of HelD, that the genes encoding these enzymes are all expressed, that HelD is likely to have been acquired by horizontal gene transfer in Gram-negative Bacteroides and Gram-positive Coriobacteria and Acidimicrobiia, and that there is a third Class of HelD found in the Gram-negative Deltaproteobacteria.

\section{RESULTS AND DISCUSSION}

\section{Distribution and phylogeny of HelD}

114 Searching for HelD-like sequences using the conserved domain architecture retrieval tool (CDART;

$115 \mathrm{NCBI}$ ) portal identified $>13,000$ hits. Additional searches using NCBI BLASTP suggest that there are 116 substantially more sequences in the database, but many of these are from incomplete genomes and/or 117 metagenomic sequencing projects, making systematic identification and classification of sequences 118 unfeasible, particularly in cases where an organism carries more than one helD gene (see below). 119 Nevertheless, it is clear that HelD is widely distributed in the eubacteria, especially in the Firmicutes 120 and Actinobacteria phyla of the Gram-positive eubacterial domain. To date, we have not detected

121 HelD-like sequences in Archaea or Eucarya. Previously, Newing et al. (Newing et al., 2020) showed that HelD sequences fall into two classes, which was confirmed at the structural and functional level in comparing HelD proteins from the Firmicutes and Actinobacteria (Kouba et al., 2020, Newing et al., 2020, Pei et al., 2020). Using a wider range of carefully curated sequences from complete genomes identified from the initial CDART search, an unrooted phylogenetic tree was constructed to enable a more detailed understanding of HelD distribution and phylogeny which was compared against the RNAP RpoB ( $\beta$ ) subunit (Figure 3).

Four features are clear from this tree (Figure 3A): 1. HelD is also present in Gram-negative bacteria; 2. A third class of HelD is present in the Deltaproteobacteria; 3. In some organisms HelD has been ancestrally acquired by horizontal gene transfer; 4 . Many organisms contain more than one helD gene, with the Firmicutes, Clostridia, Acidimicrobiia, and Deltaproteobacteria having up to three, and the Actinobacteria up to five. 
Overall, the tree contains three major branches: Class I HelD sequences originating mainly from the low G+C Gram-positives and Bacteriodia, Class II HelD sequences from the high G+C Grampositives, and a novel Class III identified in Deltaproteobacteria. Interestingly, the HelD sequences from the Actinobacterial Coriobacteria class, typified by Olsenella uli that is associated with gingivitis, are all located to the Class I branch of the tree (numbers 16-20; Figure 3). Branch divergence and clustering of sequences to regions of the tree comprising Lactobacilli (numbers 14, 15, 21-24; Figure 3) and Clostridia (numbers 25-29; Figure 3) indicate that an ancestral Coriobacteria likely acquired helD genes by horizontal gene transfer from these organisms (Figure S1). That Coriobacteria are isolated from the gingival crevice, gastrointestinal and genital tracts (Clavel, 2014) is consistent with this proposition. The length of the branches suggests this horizontal transfer event occurred long ago but after the evolution of the mammalian hosts that provide environments with co-localised Lactobacilli, and that helD genes have been stably inherited and coevolved within the Coriobacteria. In addition to the helD gene from Adlercreutzia equolifaciens DSM 19450 (AEQU_1689, number 20.1; Figure 3) that clusters with those of the other Coriobacteria, A. equolifaciens contains a second helD gene (AEQU_0484, number 20.2; Figure 3) that clusters with Clostridia, suggesting it may have been acquired through a separate horizontal gene transfer event rather than through duplication and evolution of a gene inherited by a single acquisition event (Figure S1). The fact that Lactobacilli, Clostridia, and Aldercreutzia all inhabit the gastrointestinal tract make this a reasonable hypothesis. There is also some evidence that Class II HelD sequences have been acquired by horizontal gene transfer from the Actinobacteria to the Acidimicrobiia (numbers 48, 52.1 and 52.2; Figures 3 and S2). The Acidimicrobiia are a recently described class, exemplified by Acidobacterium ferrooxidans (number 48; Figure 3) that have been isolated from diverse, but generally acidic and hostile environments, and tend to grow slowly which may account for the paucity of information and diversity of species currently available. At least one species of the Acidimicrobiia, Ilumatobacter coccineus (number 52, Figure 3) contains multiple copies of helD.

Comparison of the phylogenetic tree of the RNA polymerase $\beta$ subunit RpoB with the HelD tree supports this assumption that helD genes in the Coriobacteria and Acidimicrobiia have been acquired by horizontal gene transfer from Firmicutes/Clostridia/Actinobacteria that share the same ecological niches (Figures 3A and B). Acquisition of helD genes by horizontal gene transfer in the Bacteroidia is described below.

\section{Acquisition of helD in Gram-negative Bacteroides}


HelD sequences were also identified in the phylum of Gram-negative bacteria, Bacteroides. Phylogenetically, these clustered close to HelD sequences from Clostridioides difficile (Figures 3A and S3; sequences 27-29 C. difficile, 30-35 Bacteroides). Extended analysis indicated that HelD sequences from Bacteroides and Parabacteroides (family Porphyromonadaceae) clustered closest to those from Firmicutes that are strict gut anaerobes from the order Clostridiales (Figure S4). These bacteria were from cluster IV (Ruminoccoaceae) and XIVa (Lachnospiraceae) that are abundant gut microbes associated with many aspects of good health, and the cluster XI gut pathogen $C$. difficile (Lopetuso et al., 2013, Lozupone et al., 2012, Milani et al., 2017). Since the Bacteroides and Parabacteroides are also abundant obligate gut anaerobes, this clustering suggested that helD was horizontally transferred from an anaerobic gut Firmicute, most likely from the order Clostridiales (Figure S3). Analysis of the genome context of helD genes indicated they were not (or are no longer) located in mobile genetic elements, with the exception of $B$. thetaiaotamicron, and along with their widespread distribution in Bacteroides/Parabacteroides suggests helD genes have been retained over a significant time period, indicating they serve a useful cellular function. The fact that HelD sequences identified in Bacterioides cluster with Class I sequences from the low $\mathrm{G}+\mathrm{C}$ Gram-positive bacteria rather than forming a separate Class, as seen with HelD from the Deltaproteobacteria (see below), further supports the idea that this group acquired helD genes by horizontal gene transfer due to sharing a similar environmental niche to anaerobic gut Clostridiales.

\section{A novel HelD class in Gram-negative bacteria}

The analysis presented in this work also shows that there is a third class of HelD proteins encoded by the Deltaproteobacteria (Class III, Figure 3 and 4; see below). Newing et al. (Newing et al., 2020) identified Class I and II HelD proteins based on the conservation of twelve sequence motifs. These motifs (labelled I-XII, Figure S5) are all conserved in Class III proteins (exemplified by Myxococcus xanthus HelD), despite the low overall levels of sequence similarity found in HelD proteins (Newing et al., 2020). A model of M. xanthus HelD was also generated from an unbiased screen of the protein structure database (Figure 4; see Materials and Methods). As seen with Class I and II proteins, there is a HelD-specific N-terminal domain of $\sim 50-150$ amino acids that has a long antiparallel $\alpha$-helical structure (secondary channel arm, SCA, Figure 4B) that is required to anchor HelD in the secondary channel of its cognate RNAP (Kouba et al., 2020, Newing et al., 2020, Pei et al., 2020), and the 1A helicase domain is split by the insertion of an arm-like structure (clamp arm, CA, Figures 4B and S5) that is used to bind within the primary channel of RNAP, forcing it open to aid the release of bound nucleic acids (Kouba et al., 2020, Newing et al., 2020, Pei et al., 2020). 
An absolutely conserved DWR (Asp-Trp-Arg) sequence motif was identified in the unique N-terminal domain of all HelD sequences, and determination of the structures of HelD showed that the conserved Trp residue resides within a hydrophobic pocket called the Trp-cage, important in stabilising the interaction between the N-terminal domain wedged deep into the secondary channel of RNAP and the helicase 1A domain (Newing et al., 2020). In most HelD sequences identified to date, the DWR motif is extended to DWR[A/S]P, but in Deltaproteobacterial HelDs there is an additional amino acid inserted in this motif following the R residue, i.e., DWR $\underline{X}[\mathrm{~A} / \mathrm{S}] \mathrm{P}$, which is a key defining feature of a Class III HelD (Figure S5). This additional amino acid does not appear to be highly conserved, the motif being DWRFAP in M. xanthus, DWRNAP in Haliangum ocraceum, and DWR Sorangium cellulosum, with $\mathrm{H}$ or $\mathrm{N}$ appearing to be most common. Modelling suggests this amino acid is located on a loop with its side chain in an additional pocket that may be important in reinforcing the connection between the SCA and torso, potentially through burying the conserved Trp deeper inside the Trp-cage in comparison with Class I and II HelDs (boxed green residues, Figure 4B). Structural modelling also shows the SCA of M. xanthus HelD (HelD $\mathrm{Dx})$ is longer than that of $M$. smegmatis $\left(\mathrm{HelD}_{\mathrm{MS}}\right)$, but shorter than the B. subtilis protein (HelD $\mathrm{BS}_{\mathrm{BS}}$. The tip of the $\mathrm{SCA}$ of $\mathrm{HelD}_{\mathrm{MX}}$ does not reach the active site (catalytic $\mathrm{Mg}^{2+}$, green sphere; compare dashed circles in Figure 5C-F) but would clash with the bridge helix in RNAP (teal, Figure 5D and F), potentially causing it to distort and displace the template DNA strand as seen with $\mathrm{HelD}_{\mathrm{BS}}$ (Newing et al., 2020). The RNAP trigger loop contains a large insertion in the Deltaproteobacteria ( $\beta$ 'In6, Figure 5B) similar to that seen in Gammaproteobacteria, and it was assumed this (and the $\beta \mathrm{In} 4$ insertion, Figure 5B) would sterically interfere with HelD binding to RNAP in Gram-negative bacteria. Although the trigger loop in the

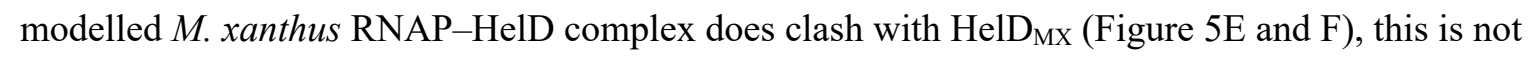
extensive and given the inherent flexibility in this domain, small conformational changes would readily enable binding as seen in Gram-positive bacteria (Kouba et al., 2020, Newing et al., 2020, Pei et al., 2020). The CA of HelD $\mathrm{MX}_{\mathrm{MX}}$ is similar in size to that of HelD $\mathrm{D}_{\mathrm{MS}}$ (although it does not contain a PCh domain; Figure 5B). The CA domain is required for clamp opening and DNA release in the Gram-positive systems, and likely will serve a similar function in Class III HelDs.

Examination of sequences retrieved from the CDART search indicated helD genes may be even more widely distributed in the Proteobacteria (including the Gammaproteobacteria), although this could not be verified by searches of complete genomes in databases such as KEGG and may represent misclassification from metagenomic sequencing projects. For example, BLASTP searches suggest hits reported as being from E. coli and Vibrio vulnificus identified from metagenomic data are in fact from Bacteroides and Bacillus, respectively ((Poyet et al., 2019), and NCBI SRA accession code: PRJNA523266). Nevertheless, it is possible that helD genes are more widely distributed in

\section{Proteobacteria.}




\section{RNAP $\delta$ subunit and HelD}

240 The Firmicutes have the smallest multi-subunit RNAPs currently known (Lane and Darst, 2010b,

241 Lane and Darst, 2010a), as well as auxiliary subunits $\delta$ and $\varepsilon$ that are not found in other bacteria

242 (Keller et al., 2014, Weiss and Shaw, 2015). In the original work characterising the function of HelD

243 as a transcription complex recycling factor, it was shown that although $\delta$ or HelD on their own

244 enhanced recycling, there was a synergistic relationship between them in B. subtilis transcription

245 recycling assays (Wiedermannova et al., 2014). Structural analysis of RNAP recycling complexes

246 shows that $\delta$ and HelD interact, as well as providing clues as to how $\delta$ could enhance the recycling

247 activity of HelD by augmenting clamp opening (Pei et al., 2020). These structural studies also

248 provided insights into how $\delta$ could facilitate transcription recycling in the absence of HelD (Miller et

249 al., 2021). Genome searches indicated that not all Firmicutes contained both helD and rpoE (encoding

250 the $\delta$ subunit) genes, and an analysis was performed based on the rpoB gene to establish whether there is segregation of genes amongst orders and/or based on natural environment (Figure 6).

In the bulk of cases, the Bacilli, Lactobacilli, Leuconostoc and Enterococci contained genes for both HelD and $\delta$, and if the gene for one protein was missing, the other was present (Figure 6). The Staphylococci were heterogeneous with species such as $S$. rostri containing both helD and rpoE genes, whereas $S$. aureus only contained the gene for the $\delta$ subunit. There is a segregation of species containing both helD and rpoE cf. rpoE only, with rpoE only present in the S. saprophyticus and $S$. aureus clusters (Takahashi et al., 1999). Species that fall within the S. hyicus-intermedius cluster (e.g., S. rostri) contained both helD and rpoE, but there were exceptions such as $S$. felis, which only contained rpoE (Figure 6). The Streptococci (order Lactobacillales) only contained the rpoE gene (Figure 6), whereas the Clostridia, except for C. (Erysipelatoclostridium) cocleatum and inoccuum, only contained helD genes (Figure 6). Thus, it appears that in the Firmicutes, especially class Bacillus, the default situation is for both rpoE and helD to be present, but the absence of one gene is compensated for by the presence of the other.

\section{Many bacteria contain multiple helD genes}

A striking observation made in the preliminary phylogenetic analysis of HelD was that some organisms contain more than one helD gene (Newing et al., 2020). This preliminary analysis has now been extended and it is clear that the presence of $>1$ helD is common and is found in both Grampositive and -negative organisms (Figure 3A). Using complete genome sequences, up to 5 genes 
encoding HelD have been identified (e.g. Nonomuraea sp. ATCC55076 [organism 55]; Figures 3A and S6), and organisms have been identified with 1, 2, 3, 4, or 5 helD genes. Although most contain a single helD gene, low $\mathrm{G}+\mathrm{C}$ Gram-positives and Gram-negatives were not found with $>3$, and high G+C Gram-positive Actinobacteria such as Streptomyces, Nonomuraea, and Frankia were identified with $\geq 4$ helD genes. A simple assumption is that these multiple genes are the product of amplification through recombination, and this may well be the root of their original source, but phylogenetic analysis indicates each gene is unique, and organisms with more than one helD gene tend to encode both large ( 740-850 aa) and small ( 680-720 aa) variants. The variation in sequence length is due to differences in the flanking SCA and CA domains (arms) with the core 1A and 2A helicase domains all being of similar size. This suggests the motor function of these proteins is conserved, but the function of large $v s$ small HelD variants may differ depending on the size of the SCA and CA arms. The multiple helD genes also segregate to Class I, -II, or -III according to the organism in which they are found; Class I sequences are found in Firmicutes, whereas Actinobacteria all have Class II sequences (with the exception of the Coriobacterium Adlercreutzia equolifaciens, above), and Class III sequences are found in Deltaproteobacteria. Of the Bacteroides/Parabacteroides analysed to date, all encode only a single Class I helD gene.

It was possible that some/all of the additional helD sequences represented cryptic genes that are not expressed under any conditions, or that they are differentially expressed during different growth phases or conditions, which might provide clues to potential functions. Transcriptomics data were retrieved from the Sequence Read Archive (SRA) for selected organisms containing 1 or $>1$ helD representative of all three classes of HelD, and expression levels compared relative to $r p o B$ (RNAP $\beta$ subunit) and another housekeeping gene (SF1 helicase $p c r A / u v r D)$. In all cases, all of the helD genes were expressed, often at an approximately similar level to $p c r A / u v r D$ (Figure 7). The RNA-seq data of B. subtilis helD and pcrA obtained from experiments by Revilla-Guarinos et al. (Revilla-Guarinos et al., 2020) to examine changes in gene expression in a model soil organism on exposure to the antifungal agent amphotericin B produced by Streptomycetes closely matched that of the oligonucleotide hybridisation transcriptomics data of Nicolas et al. (Nicolas et al., 2012) and showed the level of helD expression was not influenced by amphotericin B and was $\sim 3 \%$ that of $r p o B$ (Figure $7 \mathrm{~A}$ ). This is also consistent with proteomics analysis indicating HelD is present at $\sim 6 \%$ the level of RNAP (Delumeau et al., 2011). B. cereus contains two helD genes and the data set from strain F837/76 (Jessberger et al., 2019) grown in the presence and absence of mucin that can influence toxin production shows that both copies (one large, one small variant) are expressed, albeit at low levels, and expression is not significantly affected on exposure to mucin (Figure 7B). C. perfringens also contains two Class I helD genes, labelled CPE_0599 (small; 706 aa) and CPE_1619 (large; 763 aa) in strain 13, and expression levels were determined from datasets of cells grown in brain heart infusion (BHI) and a rich medium 
developed for the optimal growth of fastidious anaerobes, fastidious anaerobe broth $+2 \%$ glucose (FABG) medium (Soncini et al., 2020). Both genes were expressed at levels comparable to helD in $B$. subtilis, and their cognate $\operatorname{prcA} /$ uvrD, although CPE_0599 expression increased $\sim 3$-fold and CPE_1619 expression decreased in FABG medium compared to BHI medium (Figure 6C).

S. coelicolor A2(3) contains four Class II helD genes, two encoding large (SCO_2952 744 aa, and SCO_5439 755 aa) and two encoding small (SCO_4195680 aa, and SCO_4316 681 aa) variants. Data from a study on growth phase-dependent changes in gene expression (Jeong et al., 2016) were obtained from the SRA for analysis of helD expression and compared with $r p o B$ and $p c r A$. All four helD genes were expressed with relative levels changing $\sim 2$-fold dependent on the growth phase (Figure 7D). Expression levels were generally highest during mid-log and transition, and lowest during late and stationary phases, with modest changes between the ratios of expression of the different gene copies at all stages. The RNA-seq data set for M. smegmatis comparing changes in gene expression on deletion of the transcript cleavage factor GreA that is important in rescuing backtracked RNAP (Feng et al., 2020) showed that expression of the single helD gene was substantially higher than in most other organisms, at about $25 \%$ the level of $r p o B$ suggesting HelD may be particularly abundant in the Mycobacteria (Figure 7E). The expression levels of helD were similar in the presence and absence of gre $A$ indicating each factor acts on stalled transcription complexes independently of each other.

Analysis of RNA-seq data showed helD genes were also expressed in Gram-negative M. xanthus and B. vulgatus (Figure $7 \mathrm{~F}$ and $\mathrm{G}$ ), showing that despite the structural differences adjacent to the HelD interaction sites in the $\beta$ and $\beta$ ' subunits of RNAP from these organisms, HelDs are expressed and likely able to bind and functionally interact with their cognate RNAPs. The data for M. xanthus were obtained to examine changes in gene expression during the development of fruiting bodies and spores. It is interesting to note that expression of helD in M. xanthus increases during development of spores (not to be confused with sporulation in the Firmicutes) and may point to a role in storage of inactive RNAP during dormancy as has been proposed for B. subtilis HelD (Pei et al., 2020). The study in $B$. vulgatus was designed to investigate the effect on gene expression of exogenous thiamine that may be important in niche establishment in the gut. Therefore, in most/all organisms that contain helD gene(s), it/they are expressed. The reason why one organism contains a single gene and closely related species contain more than one (e.g. B. subtilis and B. cereus, Figure 6A and B) is currently not clear, but the expression data would suggest that each isoform has a functional role to play in the cell, and there is not a significant difference in the expression of large $v s$ small helD variants. 
In this work we have examined the phylogenetic distribution and classification of the transcription recycling factor HelD in detail and have identified a new class restricted to the Deltaproteobacteria. In addition, it appears helD genes have been acquired by horizontal transfer on at least three occasions; Bacteroides have acquired helD from the Clostridiales, whereas the Coriobacteria have acquired it from the Lactobacilli and Clostridiales. The gut microbiome is known as an environment conducive to horizontal gene transfer, especially with respect to distribution of antibiotic resistance genes (McInnes et al., 2020), and given that Bacteroides, Lactobacilli, Clostridiales, and Coriobacteria are all common in the gut microbiome, it appears A. equolifaciens has aquired helD genes from gut microorganisms on two separate occasions. Indeed, an unusual feature of helD genes is that many organisms contain multiple paralogues, and that all versions are expressed. Why some organisms have a single gene for helD while a closely related species has multiple expressed copies is unclear, and this will make a fascinating avenue for future research. It is interesting to note that actinobacteria, such as Streptomyces, Frankia, and Nonomuraea (numbers 50, 51, 54 and 55; Figure. 1) that are known producers of valuable bioactive compounds used as antibiotics and anti-cancer drugs contained the largest number of helD genes (4-5). It is possible that the 5 helD genes in Nonomuraea (number 55, Figure 1), that is a known producer of DNA-intercalating agents (Sungthong and Nakaew, 2015) are involved in genome maintenance through recycling stalled transcription complexes during production of these compounds. Nonomuraea and other Actinomycetales sometimes have a second $r p o B$ gene that confers resistance of RNAP to compounds such as rifampicin and sorangicin that is induced by stress and is associated with production of secondary metabolites (D'Argenio et al., 2016). The combination of multiple HelD isoforms with drug resistant RNAP may be important in this proposed genome maintenance activity. In some organisms, such as $M$. abcessus and S. venezuaelae helD expression is induced in the presence of the antibiotic rifampicin, conferring resistance, and this is associated with the presence of a DNA sequence called the Rifamycin Associated Element (RAE) found upstream of the gene (Hurst-Hess et al., 2021,

368 Surette et al., 2021). It is proposed that the tip of the PCh loop is able to physically remove rifampicin

369 bound to the RNAP $\beta$ subunit in a pocket close to the active site. In S. venezuelae (organism \#50,

370 Figure 3) that has five helD genes, only one (SVEN_6029, \#50.3) is induced in the presence of rifampicin and has an upstream RAE (Surette et al., 2021). It is interesting to note that despite encoding a rifampicin resistant RNAP $\beta$ subunit, Nonomuraea also has an RAE located directly upstream of helD NOA_42280 (\#55.3; Figure S5). 
Investigation of the distribution of helD genes with upstream RAEs revealed they were clustered to two sub-branches of the Actinobacteria (Figure S7) that may be considered the HelR grouping based on the nomenclature of these proteins by (Hurst-Hess et al., 2021, Surette et al., 2021). It should be noted that clearly identifiable RAEs could not be found upstream of all the genes in the HelR group, including for Frankia alni, Nocardia brasiliensis or Mycolicibacterium phlei (54.2, 56.2, and 64, respectively; Figure 3 and S2). Rifampicin has also been observed to induce helD expression in the low $\mathrm{G}+\mathrm{C}$ Gram-positive $B$. subtilis, but this induction does not confer resistance to the drug (Hutter et al., 2004). Nevertheless, the ability of naturally produced antibiotics to induce expression of helD genes suggests HelD proteins have a potentially important role in preserving genome integrity and gene expression in the bacteria in which they are found.

An additional area of future research should include functional and structural studies of HelD from Gram-negative bacteria, as due to the location of lineage-specific inserts in the $\beta$ and $\beta$ ' subunits of RNAP in Gram-negatives it was assumed HelD-like proteins would bind poorly or be sterically inhibited from binding. HelD proteins represent a new class of motor enzyme involved in transcription complex recycling that are widely distributed in bacteria that make an important contribution to our understanding of the multiple different mechanisms used to resolve potentially lethal stalled transcription complexes.

Finally, it is important that genome annotation databases are updated as helD genes are often classified as $p c r A, u v r D$, or helicase IV-ATPase. Correct annotation of helD genes will enable more detailed understanding of the distribution, evolution and function of this fascinating new category of transcription factor.

\section{EXPERIMENTAL PROCEDURES}

\section{Sequence retrieval and analysis}

The sequence of B. subtilis 168 HelD (UniProtKB ID: O32215) was used to search for homologues using the NCBI Conserved Domain Architecture Retrieval Tool (Geer et al., 2002), which identified 13,781 sequences, which were trimmed to 11,821 . To aid subsequent analyses, particularly for the study of multiple copies of helD genes, the original sequences were used to search complete reference genomes from the KEGG (https://www.kegg.jp) and JGI (https://jgi.doe.gov) databases. HelD and RpoB sequences retrieved from these complete genomes were used for subsequent phylogenetic studies. 


\section{Construction of phylogenetic trees}

410 Selected sequences were aligned using MAFFT (Katoh et al., 2002, Katoh et al., 2019) with default settings. Sequence alignments were then trimmed using Gblocks (https://ngphylogeny.fr). The best fitting model (LG) was determined using ProtTest 3 (Darriba et al., 2011) and phylogenetic trees were constructed using MrBayes 3.2 (Huelsenbeck and Ronquist, 2001, Ronquist et al., 2012), which were run until the standard deviation was below 0.01. Trees were visualised using iTol (Letunic and Bork, 2019).

\section{Transcriptome data and analysis}

Gene expression data were obtained from datasets deposited in the Sequence Read Archive (SRA; https://www.ncbi.nlm.nih.gov/sra) and were: B. subtilis 168 (Revilla-Guarinos et al., 2020); B. cereus F837/76 (Jessberger et al., 2019); Clostridium perfringens 13 (Soncini et al., 2020); Streptomyces coelicolor A3(2) (Jeong et al., 2016); Mycobacterium smegmatis MC2-155 (Feng et al., 2020); Myxococcus xanthus DK1622 (SRA accession code: PRJNA516475); Bacteroides vulgatus ATCC8482 (SRA accession code: PRJNA473003). Reads were mapped to the respective reference genome sequences, and gene expression levels were calculated in Genious Prime 2020.2.3 (https://www.geneious.com). Transcript per million (TPM) values were used for comparison of helD expression levels $c f$. rpoB, and pcrA/uvrD (for S. coelicolor A3(2)).

\section{Structure modelling}

RNAP RpoB ( $\beta$ ) and RpoC ( $\beta$ ') subunits from M. xanthus DK1622 were modelled in SWISSdefined template. The M. xanthus HelD structure was modelled using i-Tasser (Yang et al., 2015) with output model 1 (C-score -0.48) selected for presentation in this work. Structural images used in this work were prepared in ChimeraX (Pettersen et al., 2020).

\section{ACKNOWLEDGEMENTS} Romanis and Karl Hassan during the preparation of this manuscript. 


\section{AUTHOR CONTRIBUTIONS}

441 JSL and MM, acquisition, analysis and interpretation of data. AJO, analysis and interpretation of data.

442 NED, interpretation of data and writing of manuscript. PJL, conception and design of study,

443 acquisition, analysis and interpretation of data, writing of manuscript.

DATA AVAILABILITY

The hybrid M. xanthus RNAP-HelD complex model is available on request from P.J.L.

\section{SUPPORTING INFORMATION}

Supporting information is available online.

\section{FUNDING}

This work was supported by grants from the Australian Research Council (DP210100365 to P.J.L,

(P.J.L). Funding for open access charge: Australian Research Council.

\section{CONFLICT OF INTEREST}

The authors declare no conflict of interest.

\section{REFERENCES}

ADELMAN, K. \& LIS, J. T. 2012. Promoter-proximal pausing of RNA polymerase II: emerging roles in metazoans. Nat Rev Genet, 13, 720-31.

CLAVEL, T., LEPAGE, P., CHARRIER, C. 2014. The Family Coriobacteriaceae. In: ROSENBERG, E., DELONG, E.F., LORY S., STACKEBRANDT, E., THOMPSON, F. (ed.) The Prokaryotes. Berlin, Heidelberg: Springer.

D'ARGENIO, V., PETRILlO, M., PASANISI, D., PAGLIARULO, C., COLICCHIO, R., TALA, A., DE BIASE, M. S., ZANFARDINO, M., SCOLAMIERO, E., PAGLIUCA, C., GABALLO, A., CICATIELLO, A. G., CANTIELlO, P., POSTIGLIONE, I., NASO, B., BOCCIA, A., DURANTE, M., COZZUTO, L., SALVATORE, P., PAOLELLA, G., SALVATORE, F. \& ALIFANO, P. 2016. The complete $12 \mathrm{Mb}$ genome and transcriptome of Nonomuraea gerenzanensis with new insights into its duplicated "magic" RNA polymerase. Sci Rep, 6, 18. 
DARRIBA, D., TABOADA, G. L., DOALLO, R. \& POSADA, D. 2011. ProtTest 3: fast selection of best-fit models of protein evolution. Bioinformatics, 27, 1164-5.

DELUMEAU, O., LECOINTE, F., MUNTEL, J., GUILLOT, A., GUEDON, E., MONNET, V., HECKER, M., BECHER, D., POLARD, P. \& NOIROT, P. 2011. The dynamic protein partnership of RNA polymerase in Bacillus subtilis. Proteomics, 11, 2992-3001.

EPSHTEIN, V., KAMARTHAPU, V., MCGARY, K., SVETLOV, V., UEBERHEIDE, B., PROSHKIN, S., MIRONOV, A. \& NUDLER, E. 2014. UvrD facilitates DNA repair by pulling RNA polymerase backwards. Nature, 505, 372-7.

FENG, S., LIU, Y., LIANG, W., EL-SAYED AHMED, M. A. E., ZHAO, Z., SHEN, C., ROBERTS, A. P., LIANG, L., LIAO, L., ZHONG, Z., GUO, Z., YANG, Y., WEN, X., CHEN, H. \& TIAN, G. B. 2020. Involvement of Transcription Elongation Factor GreA in Mycobacterium Viability, Antibiotic Susceptibility, and Intracellular Fitness. Front Microbiol, 11, 413.

GEER, L. Y., DOMRACHEV, M., LIPMAN, D. J. \& BRYANT, S. H. 2002. CDART: protein homology by domain architecture. Genome Res, 12, 1619-23.

GHODKE, H., HO, H. N. \& VAN OIJEN, A. M. 2020. Single-molecule live-cell imaging visualizes parallel pathways of prokaryotic nucleotide excision repair. Nat Commun, 11, 1477.

GUPTA, M. K., GUY, C. P., YEELES, J. T., ATKINSON, J., BELL, H., LLOYD, R. G., MARIANS, K. J. \& MCGLYNN, P. 2013. Protein-DNA complexes are the primary sources of replication fork pausing in Escherichia coli. Proc Natl Acad Sci U S A, 110, 7252-7.

HAWKINS, M., DIMUDE, J. U., HOWARD, J. A. L., SMITH, A. J., DILLINGHAM, M. S., SAVERY, N. J., RUDOLPH, C. J. \& MCGLYNN, P. 2019. Direct removal of RNA polymerase barriers to replication by accessory replicative helicases. Nucleic Acids Res, 47, 5100-5113.

HO, H. N., VAN OIJEN, A. M. \& GHODKE, H. 2018. The transcription-repair coupling factor Mfd associates with RNA polymerase in the absence of exogenous damage. Nat Commun, 9, 1570.

HUELSENBECK, J. P. \& RONQUIST, F. 2001. MRBAYES: Bayesian inference of phylogenetic trees. Bioinformatics, 17, 754-5.

HURST-HESS, K. R., SAXENA, A. \& GHOSH, P. 2021. Mycobacterium abscessus HelR interacts with RNA Polymerase to confer intrinsic rifamycin resistance. bioRxiv, 2021.05.10.443476.

HUTTER, B., FISCHER, C., JACOBI, A., SCHAAB, C. \& LOFERER, H. 2004. Panel of Bacillus subtilis reporter strains indicative of various modes of action. Antimicrob Agents Chemother, 48, 2588-94.

JEONG, Y., KIM, J. N., KIM, M. W., BUCCA, G., CHO, S., YOON, Y. J., KIM, B. G., ROE, J. H., KIM, S. C., SMITH, C. P. \& CHO, B. K. 2016. The dynamic transcriptional and translational landscape of the model antibiotic producer Streptomyces coelicolor A3(2). Nat Commun, 7, 11605.

JESSBERGER, N., DIETRICH, R., MOHR, A. K., DA RIOL, C. \& MARTLBAUER, E. 2019. Porcine Gastric Mucin Triggers Toxin Production of Enteropathogenic Bacillus cereus. Infect Immun, 87.

JUMPER, J., EVANS, R., PRITZEL, A., GREEN, T., FIGURNOV, M., RONNEBERGER, O., TUNYASUVUNAKOOL, K., BATES, R., ZIDEK, A., POTAPENKO, A., BRIDGLAND, A., MEYER, C., KOHL, S. A. A., BALLARD, A. J., COWIE, A., ROMERA-PAREDES, B., NIKOLOV, S., JAIN, R., ADLER, J., BACK, T., PETERSEN, S., REIMAN, D., CLANCY, E., ZIELINSKI, M., STEINEGGER, M., PACHOLSKA, M., BERGHAMMER, T., BODENSTEIN, S., SILVER, D., VINYALS, O., SENIOR, A. W., KAVUKCUOGLU, K., KOHLI, P. \& HASSABIS, D. 2021. Highly accurate protein structure prediction with AlphaFold. Nature.

KANG, J. Y., LLEWELLYN, E., CHEN, J., OLINARES, P. D. B., BREWER, J., CHAIT, B. T., CAMPBELL, E. A. \& DARST, S. A. 2021. Structural basis for transcription complex disruption by the Mfd translocase. Elife, 10.

KANG, J. Y., OLINARES, P. D., CHEN, J., CAMPBELL, E. A., MUSTAEV, A., CHAIT, B. T., GOTTESMAN, M. E. \& DARST, S. A. 2017. Structural basis of transcription arrest by coliphage HK022 Nun in an Escherichia coli RNA polymerase elongation complex. Elife, 6.

KATOH, K., MISAWA, K., KUMA, K. \& MIYATA, T. 2002. MAFFT: a novel method for rapid multiple sequence alignment based on fast Fourier transform. Nucleic Acids Res, 30, 3059-66. 
KATOH, K., ROZEWICKI, J. \& YAMADA, K. D. 2019. MAFFT online service: multiple sequence alignment, interactive sequence choice and visualization. Brief Bioinform, 20, 1160-1166.

KELLER, A. N., YANG, X., WIEDERMANNOVA, J., DELUMEAU, O., KRASNY, L. \& LEWIS, P. J. 2014. epsilon, a new subunit of RNA polymerase found in gram-positive bacteria. $J$ Bacteriol, 196, 3622-32.

KOUBA, T., KOVAL, T., SUDZINOVA, P., POSPISIL, J., BREZOVSKA, B., HNILICOVA, J., SANDEROVA, H., JANOUSKOVA, M., SIKOVA, M., HALADA, P., SYKORA, M., BARVIK, I., NOVACEK, J., TRUNDOVA, M., DUSKOVA, J., SKALOVA, T., CHON, U., MURAKAMI, K. S., DOHNALEK, J. \& KRASNY, L. 2020. Mycobacterial HelD is a nucleic acids-clearing factor for RNA polymerase. Nat Commun, 11, 6419.

KOVAL, T., SUDZINOVA, P., PERHACOVA, T., TRUNDOVA, M., SKALOVA, T., FEJFAROVA, K., SANDEROVA, H., KRASNY, L., DUSKOVA, J. \& DOHNALEK, J. 2019. Domain structure of HelD, an interaction partner of Bacillus subtilis RNA polymerase. FEBS Lett, 593, 996-1005.

LANE, W. J. \& DARST, S. A. 2010a. Molecular evolution of multisubunit RNA polymerases: sequence analysis. J Mol Biol, 395, 671-85.

LANE, W. J. \& DARST, S. A. 2010b. Molecular evolution of multisubunit RNA polymerases: structural analysis. J Mol Biol, 395, 686-704.

LE, T. T., YANG, Y., TAN, C., SUHANOVSKY, M. M., FULBRIGHT, R. M., JR., INMAN, J. T., LI, M., LEE, J., PERELMAN, S., ROBERTS, J. W., DEACONESCU, A. M. \& WANG, M. D. 2018. Mfd Dynamically Regulates Transcription via a Release and Catch-Up Mechanism. Cell, 172, 344-357 e15.

LETUNIC, I. \& BORK, P. 2019. Interactive Tree Of Life (iTOL) v4: recent updates and new developments. Nucleic Acids Res, 47, W256-W259.

LIU, B., ZUO, Y. \& STEITZ, T. A. 2015. Structural basis for transcription reactivation by RapA. Proc Natl Acad Sci US A, 112, 2006-10.

LOPETUSO, L. R., SCALDAFERRI, F., PETITO, V. \& GASBARRINI, A. 2013. Commensal Clostridia: leading players in the maintenance of gut homeostasis. Gut Pathog, 5, 23.

LOZUPONE, C. A., STOMBAUGH, J. I., GORDON, J. I., JANSSON, J. K. \& KNIGHT, R. 2012. Diversity, stability and resilience of the human gut microbiota. Nature, 489, 220-30.

MCINNES, R. S., MCCALLUM, G. E., LAMBERTE, L. E. \& VAN SCHAIK, W. 2020. Horizontal transfer of antibiotic resistance genes in the human gut microbiome. Curr Opin Microbiol, 53, 35-43.

MILANI, C., DURANTI, S., BOTTACINI, F., CASEY, E., TURRONI, F., MAHONY, J., BELZER, C., DELGADO PALACIO, S., ARBOLEYA MONTES, S., MANCABELLI, L., LUGLI, G. A., RODRIGUEZ, J. M., BODE, L., DE VOS, W., GUEIMONDE, M., MARGOLLES, A., VAN SINDEREN, D. \& VENTURA, M. 2017. The First Microbial Colonizers of the Human Gut: Composition, Activities, and Health Implications of the Infant Gut Microbiota. Microbiol Mol Biol Rev, 81.

MILLER, M., OAKLEY, A. J. \& LEWIS, P. J. 2021. RNA polymerases from Low G+C Gram Positive Bacteria. bioRxiv, 2021.06.06.447298.

NEWING, T. P., OAKLEY, A. J., MILlER, M., DAWSON, C. J., BROWN, S. H. J., BOUWER, J. C., TOLUN, G. \& LEWIS, P. J. 2020. Molecular basis for RNA polymerase-dependent transcription complex recycling by the helicase-like motor protein HelD. Nat Commun, 11, 6420.

NICOLAS, P., MADER, U., DERVYN, E., ROCHAT, T., LEDUC, A., PIGEONNEAU, N., BIDNENKO, E., MARCHADIER, E., HOEBEKE, M., AYMERICH, S., BECHER, D., BISICCHIA, P., BOTELLA, E., DELUMEAU, O., DOHERTY, G., DENHAM, E. L., FOGG, M. J., FROMION, V., GOELZER, A., HANSEN, A., HARTIG, E., HARWOOD, C. R., HOMUTH, G., JARMER, H., JULES, M., KLIPP, E., LE CHAT, L., LECOINTE, F., LEWIS, P., LIEBERMEISTER, W., MARCH, A., MARS, R. A., NANNAPANENI, P., NOONE, D., POHL, S., RINN, B., RUGHEIMER, F., SAPPA, P. K., SAMSON, F., SCHAFFER, M., SCHWIKOWSKI, B., STEIL, L., STULKE, J., WIEGERT, T., DEVINE, K. M., WILKINSON, A. J., VAN DIJL, J. M., HECKER, M., VOLKER, U., BESSIERES, P. 
\& NOIROT, P. 2012. Condition-dependent transcriptome reveals high-level regulatory architecture in Bacillus subtilis. Science, 335, 1103-6.

PEI, H. H., HILAL, T., CHEN, Z. A., HUANG, Y. H., GAO, Y., SAID, N., LOLL, B., RAPPSILBER, J., BELOGUROV, G. A., ARTSIMOVITCH, I. \& WAHL, M. C. 2020. The delta subunit and NTPase HelD institute a two-pronged mechanism for RNA polymerase recycling. Nat Commun, 11, 6418.

PETTERSEN, E. F., GODDARD, T. D., HUANG, C. C., MENG, E. C., COUCH, G. S., CROLL, T. I., MORRIS, J. H. \& FERRIN, T. E. 2020. UCSF ChimeraX: Structure Visualization for Researchers, Educators, and Developers. Protein Sci.

POMERANTZ, R. T. \& O'DONNELL, M. 2008. The replisome uses mRNA as a primer after colliding with RNA polymerase. Nature, 456, 762-6.

POMERANTZ, R. T. \& O'DONNELL, M. 2010. Direct restart of a replication fork stalled by a headon RNA polymerase. Science, 327, 590-2.

POYET, M., GROUSSIN, M., GIBBONS, S. M., AVILA-PACHECO, J., JIANG, X., KEARNEY, S. M., PERROTTA, A. R., BERDY, B., ZHAO, S., LIEBERMAN, T. D., SWANSON, P. K., SMITH, M., ROESEMANN, S., ALEXANDER, J. E., RICH, S. A., LIVNY, J., VLAMAKIS, H., CLISH, C., BULLOCK, K., DEIK, A., SCOTT, J., PIERCE, K. A., XAVIER, R. J. \& ALM, E. J. 2019. A library of human gut bacterial isolates paired with longitudinal multiomics data enables mechanistic microbiome research. Nat Med, 25, 14421452.

RAGHEB, M. N., MERRIKH, C., BROWNING, K. \& MERRIKH, H. 2021. Mfd regulates RNA polymerase association with hard-to-transcribe regions in vivo, especially those with structured RNAs. Proc Natl Acad Sci U S A, 118.

REVILLA-GUARINOS, A., DURR, F., POPP, P. F., DORING, M. \& MASCHER, T. 2020. Amphotericin B Specifically Induces the Two-Component System LnrJK: Development of a Novel Whole-Cell Biosensor for the Detection of Amphotericin-Like Polyenes. Front Microbiol, 11, 2022.

ROCHA, E. P. C. 2004. The replication-related organization of bacterial genomes. Microbiology, 150, 1609-1627.

RONQUIST, F., TESLENKO, M., VAN DER MARK, P., AYRES, D. L., DARLING, A., HOHNA, S., LARGET, B., LIU, L., SUCHARD, M. A. \& HUELSENBECK, J. P. 2012. MrBayes 3.2: efficient Bayesian phylogenetic inference and model choice across a large model space. Syst Biol, 61, 539-42.

SABA, J., CHUA, X. Y., MISHANINA, T. V., NAYAK, D., WINDGASSEN, T. A., MOONEY, R. A. \& LANDICK, R. 2019. The elemental mechanism of transcriptional pausing. Elife, 8.

SHI, J., WEN, A., ZHAO, M., JIN, S., YOU, L., SHI, Y., DONG, S., HUA, X., ZHANG, Y. \& FENG, Y. 2020. Structural basis of Mfd-dependent transcription termination. Nucleic Acids Res, 48, 11762-11772.

SIKOVA, M., WIEDERMANNOVA, J., PREVOROVSKY, M., BARVIK, I., SUDZINOVA, P., KOFRONOVA, O., BENADA, O., SANDEROVA, H., CONDON, C. \& KRASNY, L. 2020. The torpedo effect in Bacillus subtilis: RNase J1 resolves stalled transcription complexes. EMBO J, 39, e102500.

SONCINI, S. R., HARTMAN, A. H., GALLAGHER, T. M., CAMPER, G. J., JENSEN, R. V. \& MELVILLE, S. B. 2020. Changes in the expression of genes encoding type IV pili-associated proteins are seen when Clostridium perfringens is grown in liquid or on surfaces. BMC Genomics, 21, 45.

SUNGTHONG, R. \& NAKAEW, N. 2015. The genus Nonomuraea: A review of a rare actinomycete taxon for novel metabolites. $J$ Basic Microbiol, 55, 554-65.

SURETTE, M. D., WAGLECHNER, N., KOTEVA, K. \& WRIGHT, G. D. 2021. HelR is a helicaselike protein that protects RNA polymerase from rifamycin antibiotics. bioRxiv, 2021.05.10.443488.

TAKAHASHI, T., SATOH, I. \& KIKUCHI, N. 1999. Phylogenetic relationships of 38 taxa of the genus Staphylococcus based on 16S rRNA gene sequence analysis. Int J Syst Bacteriol, $49 \mathrm{Pt}$ $2,725-8$. 
URRUTIA-IRAZABAL, I., AULT, J. R., SOBOTT, F., SAVERY, N. J. \& DILLINGHAM, M. S. 2021. Analysis of the PcrA-RNA polymerase complex reveals a helicase interaction motif and a role for PcrA/UvrD helicase in the suppression of R-loops. Elife, 10.

WATERHOUSE, A., BERTONI, M., BIENERT, S., STUDER, G., TAURIELLO, G., GUMIENNY, R., HEER, F. T., DE BEER, T. A. P., REMPFER, C., BORDOLI, L., LEPORE, R. \& SCHWEDE, T. 2018. SWISS-MODEL: homology modelling of protein structures and complexes. Nucleic Acids Res, 46, W296-W303.

WEISS, A. \& SHAW, L. N. 2015. Small things considered: the small accessory subunits of RNA polymerase in Gram-positive bacteria. FEMS Microbiol Rev, 39, 541-54.

WESTBLADE, L. F., CAMPBELL, E. A., PUKHRAMBAM, C., PADOVAN, J. C., NICKELS, B. E., LAMOUR, V. \& DARST, S. A. 2010. Structural basis for the bacterial transcription-repair coupling factor/RNA polymerase interaction. Nucleic Acids Res, 38, 8357-69.

WIEDERMANNOVA, J., SUDZINOVA, P., KOVAL, T., RABATINOVA, A., SANDEROVA, H., RAMANIUK, O., RITTICH, S., DOHNALEK, J., FU, Z., HALADA, P., LEWIS, P. \& KRASNY, L. 2014. Characterization of HelD, an interacting partner of RNA polymerase from Bacillus subtilis. Nucleic Acids Res, 42, 5151-63.

WOOD, E. R. \& MATSON, S. W. 1987. Purification and characterization of a new DNA-dependent ATPase with helicase activity from Escherichia coli. J Biol Chem, 262, 15269-76.

YANG, J., YAN, R., ROY, A., XU, D., POISSON, J. \& ZHANG, Y. 2015. The I-TASSER Suite: protein structure and function prediction. Nat Methods, 12, 7-8. 


\begin{tabular}{|l|l|l|l|l|l|l|}
\hline $1 \mathrm{~A}(1)$ & $1 \mathrm{~B}$ & $1 \mathrm{~A}(2)$ & $2 \mathrm{~A}(1)$ & $2 \mathrm{~B}$ & $2 \mathrm{~A}(2)$ & \\
\hline
\end{tabular}

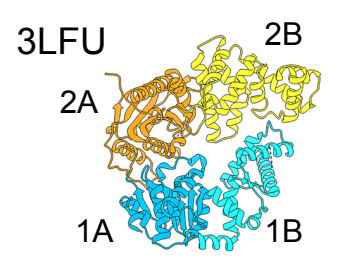

Helicase IV

\begin{tabular}{|l|l|l|l|l|}
\hline NTD & $1 \mathrm{~A}(1)$ & $1 \mathrm{~B}$ & $1 \mathrm{~A}(2)$ & $2 \mathrm{~A}$ \\
\hline
\end{tabular}
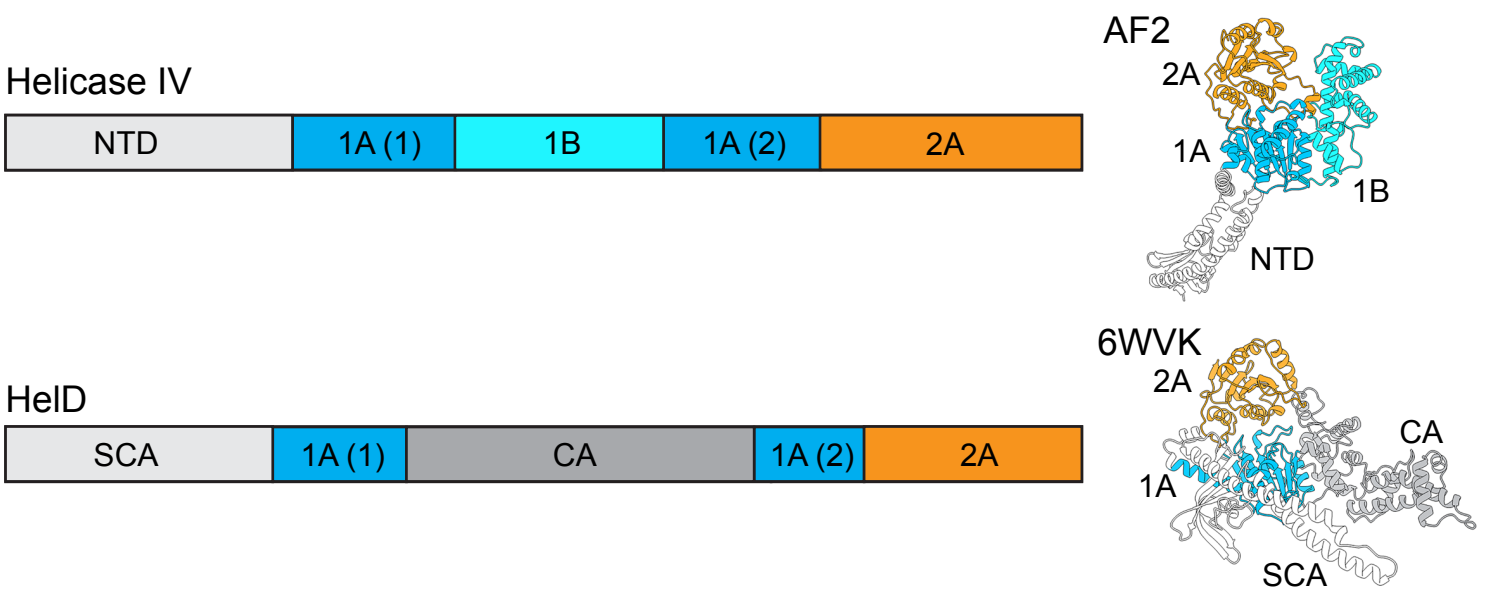

658

659 Figure 1. Relationship between UvrD/PcrA and helicase IV/HelD proteins. Left side shows linear 660 representations of the domain organisation of superfamily 1 (SF1) helicase UvrD/PcrA (top),

661 Escherichia coli helicase IV (middle) and B. subtilis HelD (bottom). Right hand side shows structures, 662 aligned via their 1A and 2A domains, with domains coloured corresponding to the left panels. Top, 663 UvrD (PDB ID 3LFU); middle, helicase IV (AlphaFold2 model, AF2); bottom, HelD (taken from 664 RNAP-HelD complex PDB ID 6WVK). 1A, B, 2A and 2B refer to conserved SF1 helicase domains. 665 NTD, SCA and CA refer to the AlphaFold2 modelled N-terminal domain of helicase IV and the 666 secondary channel arm and clamp arm of HelD, respectively. 
A

\section{B. subtilis}

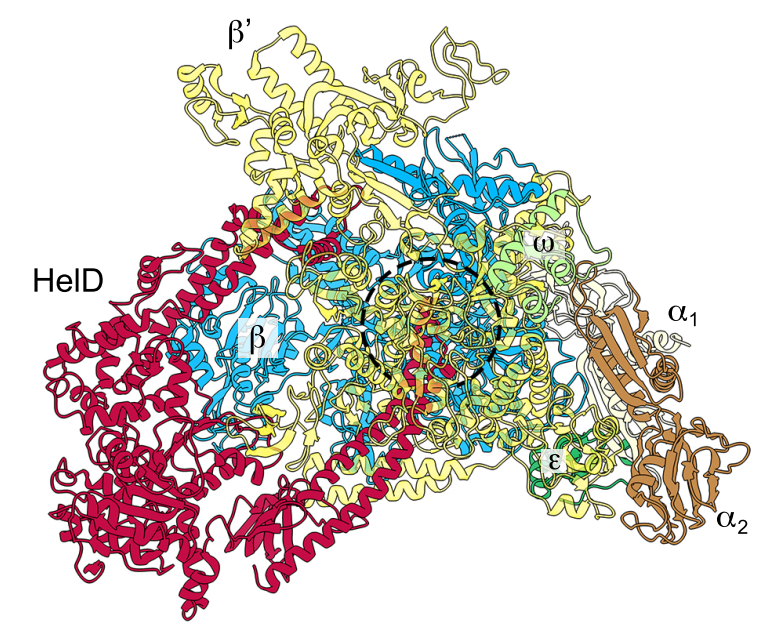

C

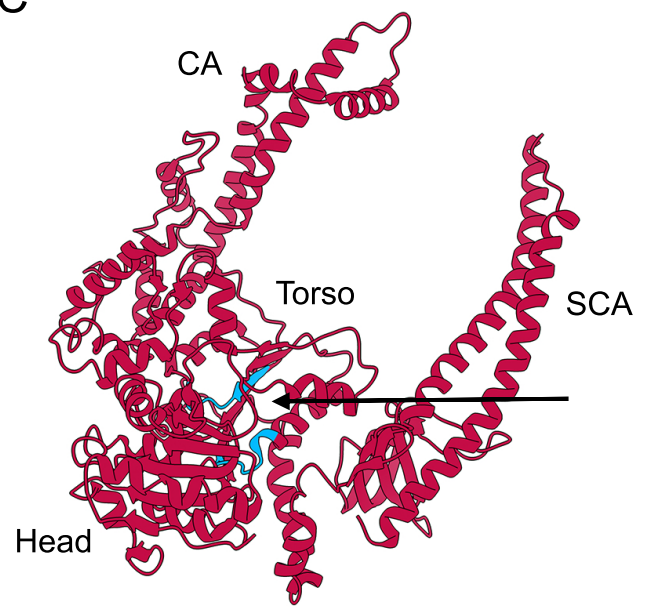

ATP
B

\section{M. smegmatis}

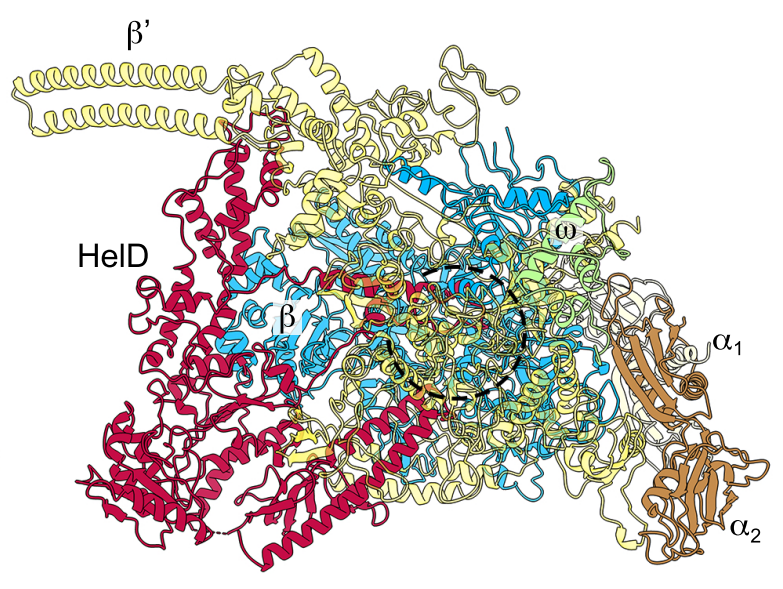
Binding

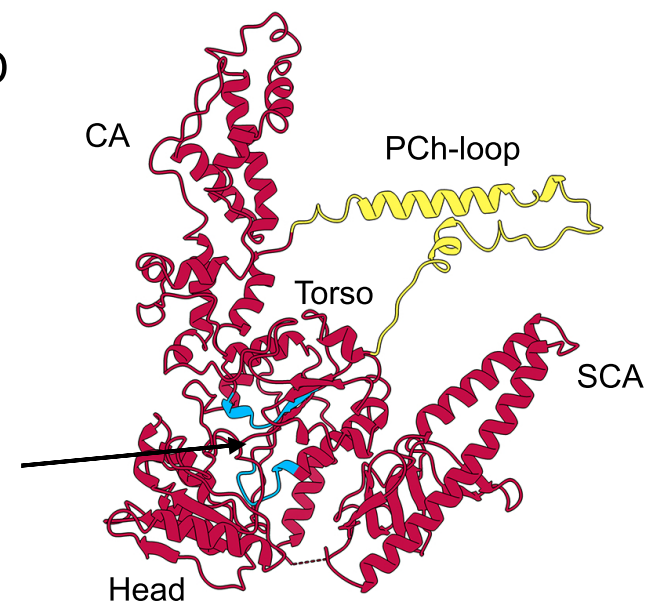

Figure 2. The two known structural classes of HelD. Panel A shows the structure of the B. subtilis RNAP-Class I HelD complex (PDB ID 6WVK). Panel B shows the M. smegmatis RNAP-Class II HelD complex (PDB ID 6YYS; state II). RNAP subunits and HelDs are coloured identically in both panels with the transparency of the $\beta$ ' subunit set at $50 \%$ so that HelD structures adjacent to the RNAP active site region (dashed circles) can be more easily visualised. Panels C and D show HelD structures from Panels A and B, respectively, with the ATP binding site coloured in blue and the PChloop from M. smegmatis HelD coloured in yellow (see text for details). 

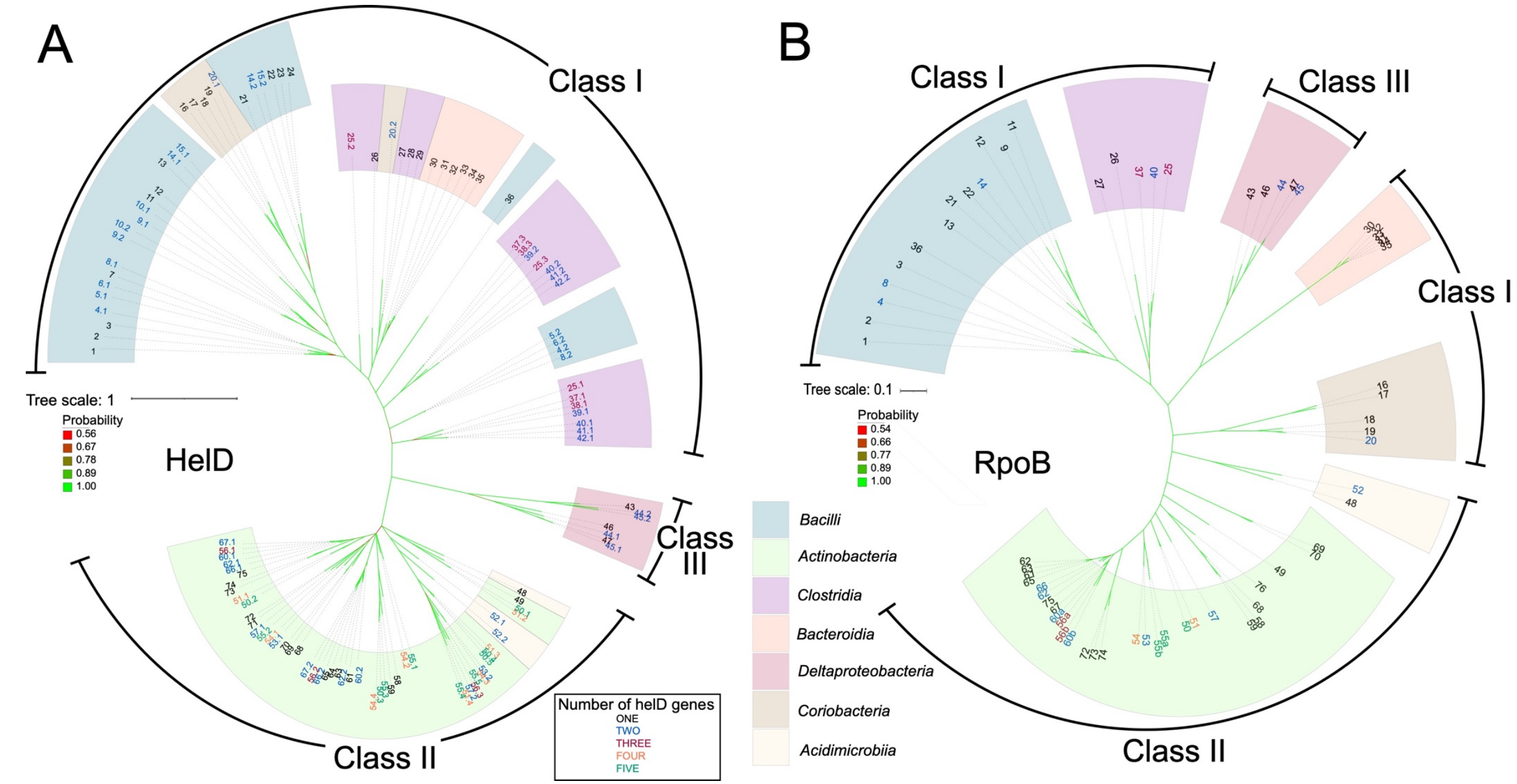
Figure 3. Unrooted phlyogenetic trees of HelD (A) and RpoB (B) sequences constructed by Bayesean analysis. Tree scale representing amino acid substitutions per site, and bootstrap probability values (red least, to green most, probable) are on the left. The HelD class into which sequences fall is indicated in the outer circles as Class I, -II and -III. Coloured arcs indicate the bacterial classes into which the HelD sequences fall; teal, Firmicutes; pale green, Actinobacteria; purple, Clostridia; orange, Bacteroidia; red, Deltaproteobacteria; brown, Coriobacteria; pale yellow, Acidimicrobilia. Individual organisms and HelD sequences are numbered (largest to smallest) and colour coded starting clockwise from Bacillus subtilis. Organism numbers with one HelD are numbered in black; two, blue; three, red; four, orange; five, green and are listed as follows with gene identifiers and protein length (aa) in brackets: 1 Bacillus subtilis 168 (BSU_33450, 774aa). 2 Bacillus licheniformis ATCC 14580 (bli_00699, 776aa). 3 Bacillus megaterium DSM 319 (BMD_3869, 772aa). 4 Bacillus cereus ATCC10987 (\#1 BCE_3516, 768 aa;\#2 BCE_2839, 689 aa). 5 Bacillus anthracis AMES (\#1 BA_1040, 776 aa;\#2 BA_2814, 689 aa). 6 Bacillus cereus AH187 (\#1 BCAH187_A1206, 777 aa;\#2 BCAH187_A2861, 689 aa). 7 Bacillus cereus ATCC14579 (BC_1041, 777 aa). 8 Bacillus thuringiensis Bt407 (\#1 btg_c11000, 778aa;\#2 btg_c29280,691aa). 9 Lactobacillus plantarum WCFS1 (\#1 1pl_0432, $769 a a ; \# 2$ 1pl_0910, 768aa). 10 Lactobacillus rhamnosus GG (\#1 1rh_01975, 763aa; \#2 1rh_02619, 762aa). 11 Leuconostoc lactis WiKim40 (11f_04535, $788 \mathrm{aa).} \mathrm{12} \mathrm{Lactobacillus} \mathrm{acidophilus}$ NCFM (lac_1676, 687aa). 13 Carnobacterium inhibens subsp. Gilchinskyi WN1359 (caw_09345, 800aa). 14 Enterococcus faecium Aus0004 (\#1 EFAU004_01304, 759 aa; \#2 EFAU004_00387, 711 aa). 15 Enterococcus faecium DO (\#1 HMPREF0351_10989, 759 aa; \#2 HMPREF0351_10397, 711 aa). 16 Olsenella uli DSM 7084 (OLS_0501, 731aa). 17 Atopobium parvulum DSM 20469 (Apar_0360, 736 aa). 18 Slackia heliotrinireducens DSM 20476: (Shel_05840 (698aa). 19 Eggerthella lenta DSM 2243(Elen_2835, 716aa). 20 Adlercreutzia equolifaciens DSM 19450 (\#1 AEQU_1689, 761 aa; \#2 AEQU_0484, 733aa). 21 Vagococcus teuberi (vte_03205, 717aa). 22 Enterococcus faecalis V583 (EF_0933, 732 aa). 23 Enterococcus faecalis DENG1 (DENG_00988, 732 aa). 24 Enterococcus faecalis OG1RF (OG1RF_10660, 740 aa). 25 Clostridium beijerinckii NCIMB 8052 (\#1 cbe_2947, 755aa; \#2 cbe_2724, 745aa; \#3 cbe_4782, 724aa). 26 Epulopiscium sp. N.t. morphotype B (EPU_RS03295, 735aa). 27 Clostridioides difficile 630 (CD630_04550, 704 aa). 28 Clostridioides difficile RM20291 (CDR20291_0396, 704 aa). 29 Clostridioides difficile CD196 (CD196_0410, 704 aa). 30 Bacteroides vulgatus ATCC 8482 (BVU_3010 (671aa). 31 Bacteroides caccae ATCC 43185 (CGC64_00555, 683aa). 32 Bacteroides cellulosilyticus WH2 (BcelWH2_01491, 693aa). 33 Bacteroides thetaiotaomicron VPI-5482 (BT_1890, 686aa). 34 Bacteroides ovatus ATCC 8483 (Bovatus_02598 (687aa). 35 Bacteroides xylanisolvens XB1A (BXY_17560, 687aa). 36 Staphylococcus delphini NCTC12225 (sdp_01978, $681 \mathrm{aa).} 37$ Clostridium botulinuim A ATCC3502 (\#1 CBO_2904, 763 aa; \#3 CBO_3341, 709 aa). 38 Clostridium botulinuim A ATCC19377 (\#1 CLB_2867, 763 aa; \#3 CLB_3399, 709 aa). 39 Clostridium botulinuim B1 Okra (\#1 CLD_1639, 763 aa;\#2 CLD_1179, 709 aa). 40 Clostridium perfringens 13 (\#1 CPE_1619, 763 aa; \#2 CPE_0599, 706 aa). 41 
Clostridium perfringens ATCC13124 (\#1 CPF_1872, 763 aa; \#2 CPF_0580, 706 aa). 42 Clostridium perfringens SM101 (\#1 CPR_1591, 763 aa; \#2 CPR_0566 706 aa). 43 Myxococcus xanthus DK 1622 (MXAN_5482, 706aa). 44 Sandaracinus amylolyticus DSM 53668 (\#1 DB32_004372, 872aa;\#2 DB32_003397, 691aa). 45 Minicystis rosea DSM 2400 (\#1 A7982_09686, 743aa; \#2 A7982_06548, 703 aa). 46 Haliangium ochraceum DSM 14365 (Hoch_0025, 852aa). 47 Sorangium cellulosum So157-2 (SCE1572_03860, 747aa). 48 Acidobacterium ferrooxidans (Afer_1829, $706 a a) .49$ Cutibacterium acnes KPA171202 (PPA0733, 753aa). 50 Streptomyces venezuelae (\#1 SVEN_2719, 779aa; \#2 SVEN_5092, 747aa; \#3 SVEN_6029, 722aa; \#4 SVEN_4127, 675aa; \#5 SVEN_3939; 665aa). 51 Streptomyces coelicolor A3(2) (\#1 SCO5439, 755 aa; \#2 SCO2952, 744 aa; \#3 SCO4316, 681 aa; \#4 SCO4195, 680 aa). 52 Ilumatobacter coccineus (\#1 aym_09360, 715aa; \#2 aym_20540, 654aa). 53 Frankia casuarinae Cc13 (\#1 fra_0952, 829aa; \#2 fra_2397, 727 aa). 54 Frankia alni ACN14a (\#1 fal_1589, 939aa; \#2 fal_4723, 877aa; \#3 fal_3805; 866aa; \#4 fal_4811, 751aa). 55 Nonomuraea sp. ATCC55076 (\#1 NOA_23645, 772 aa; \#2 NOA_16240, 762 aa; \#3 NOA_42280, 715 aa; \#4 NOA_08745, 660 aa; \#5 NOA_48960, 655 aa). 56 Nocardia brasiliensis O31_020410 (\#1 nbr_012985, 776aa; \#2 nbr_020410, 731aa; \#3 nbr: O3I_005870, 699aa). 57 Kineococcus radiotolerans SRS30216 (\#1 kra_3607, 759aa; \#2 kra_0164, 684aa). 58 Microbacterium sp. PAMC 28756 (mip_00070, 717aa). 59 Mirobacterium hominis SJTG1 (mhos_01135, 744aa). 60 Nocardia farcinica IFM10152 (\#1 NFA_19060, 765aa; \#2 NFA_44160, 726aa). 61 Mycobacterium smegmatis MC2 155 (MSMEG_2174, 736 aa). 62 Rhodococcus sp. 008 (\#1 rhod_26990, 760aa; \#2 rhod_09075, 731aa). 63 Mycobacterium sp. JS623 (Mycsm_03949, 732aa). 64 Mycolicibacterium phlei (MPHL_03003, 726aa). 65 Mycobacteroides abscessus ATCC 19977 (MAB_3189c, 753aa). 66 Rhodococcus equi 103S (\#1 REQ_25070, 759aa; \#2 REQ_15310, 739aa). 67 Nocardia asteroides NCTC11293 (\#1 nad_03000, 753; \#2 nad_04408, 735aa). 68 Leifsonia xyxli subsp. Xyli CTCB07 (Lxx_20770, 787 aa). 69 Bifidobacterium longum NCC2705 (BLO_1314, 759aa). 70 Bifodobacterium bifidum PRL2010 (bbp_0546, $759 \mathrm{aa}) .71$ Brevibacterium linens BS258 (bly_10570, $743 \mathrm{aa}) .72$ Brevibacterium flavum ZL-1 (bfv_07580, 755aa). 73 Corynebacterium glutamicum ATCC13031 (CG_1555, $755 \mathrm{aa}) .74$ Corynebacterium diptheriae NTCC13129 (DIP_1156, 770aa). 75 Rhodococcus rhodochrous NCTC10210 (rrt_02795, 772aa). Nonomuraea sp. ATCC55076 (55), Nocardia brasiliensis O31_020410 (56) and Nocardia farcinica IFM10152 (60) contain two copies of the rpoB gene (numbered x.a and x.b in panel B). Copy 1 is the housekeeping $r р о B$ and copy 2 is a rifamipicin-resistant $r p o B$ expressed during antibiotic production in those organisms. 


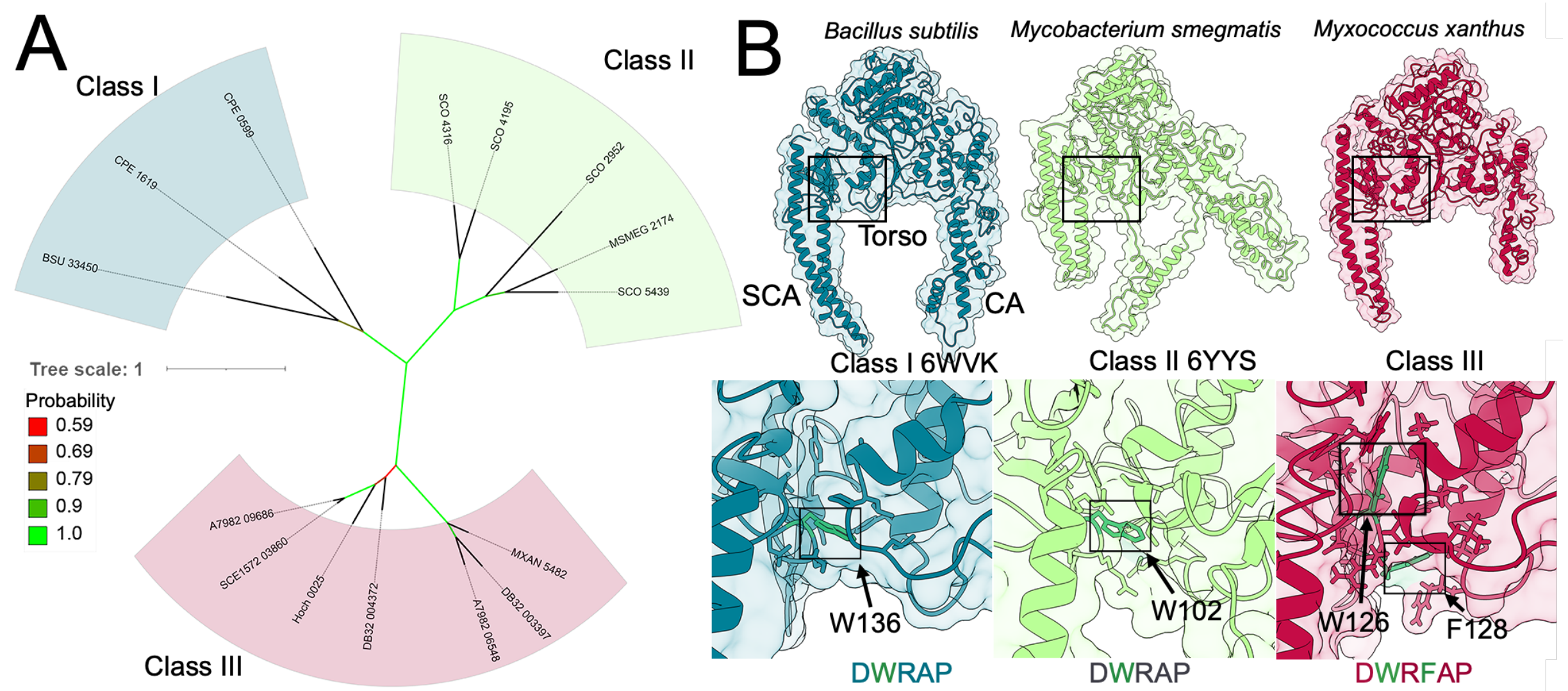

Figure 4. Three classes of HelD. Panel A shows a focused unrooted phylogenetic tree constructed using HelD sequences, with numbers (\#) as used in Figure 1A: B. subtilis 168, BSU [\#1]; C. perfringens 13, CPE [\#40]; S. coelicolor A3(2), SCO [\#51]; M. smegmatis MC2 155, MSMEG [\#61], and 
ochraceum DSM 14365, Hoch [\#46]; S. cellulosum So157-2, SCE1572 [\#47]. Tree scale representing amino acid substitutions per site, and bootstrap values are shown on the left. Colouring of bacterial classes is the same as in Figure 1. Panel B shows structures (ribbons and transparent surface representations) of whole HelD (top) and Trp-cage regions (bottom) of Class I (B. subtilis PDB ID 6WVK), Class II (M. smegmatis PDB ID 6YYS) and Class III (M. xanthus, homology model) using the same colour scheme for bacterial classes as in Figures 1 and 2A. Conserved Trp (all classes) and additional amino acid (Class III) are shown as green sticks, with other amino acids that form the cage shown in the appropriate colour for their class. 

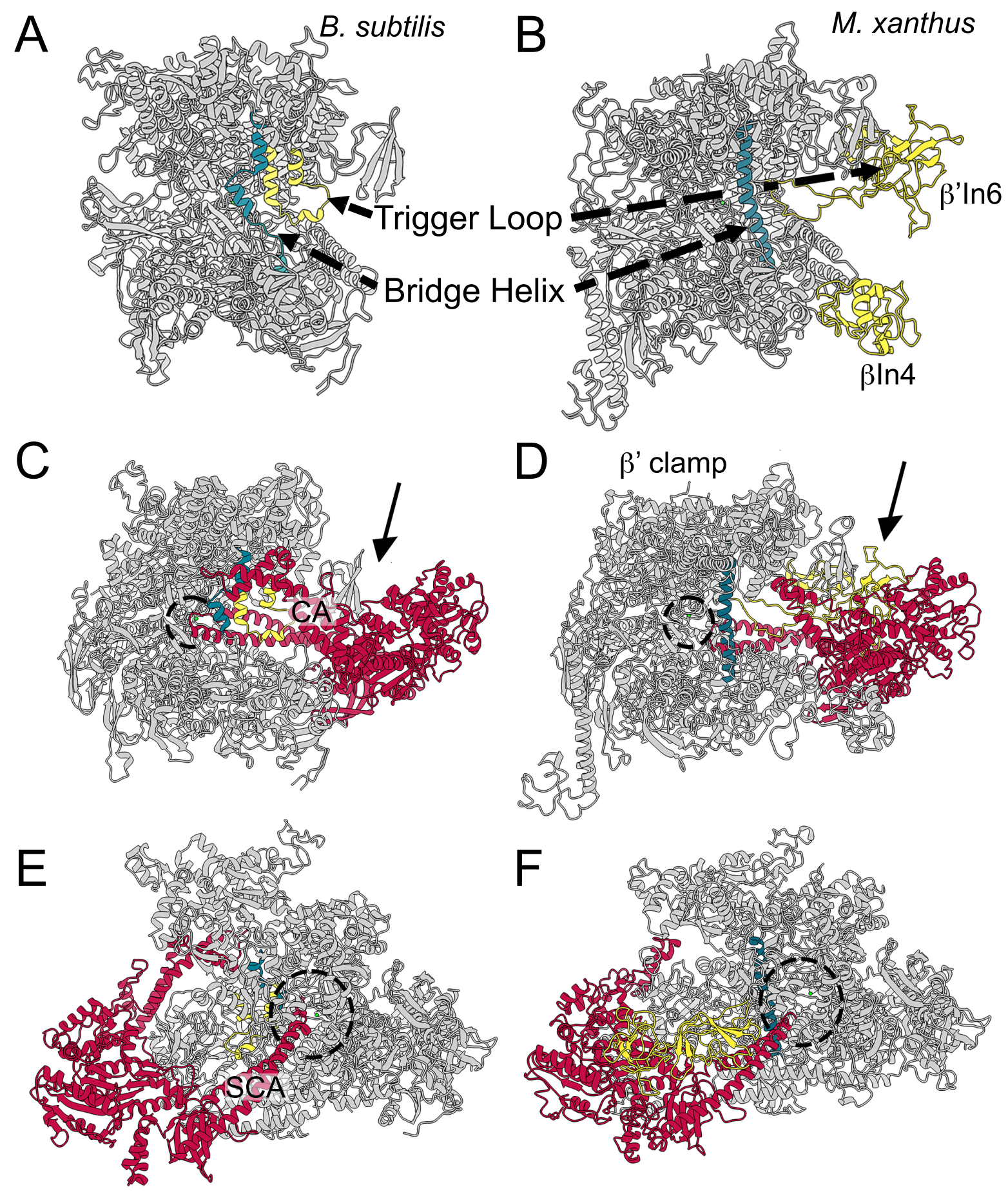

738 Figure 5. Comparison of B. subtilis RNAP-HelD complex with the M. xanthus model. Panels A and 739 B show structures of $B$. subtilis (PDB ID 6WVK) and M. xanthus (model) RNAPs in complex with 740 HelD, respectively, in which HelD has been removed to more clearly visualise elements referred to in 741 the text. The trigger loop (yellow) and bridge helix (teal) are indicated along with the lineage specific $742 \quad \beta I n 4$ (also yellow) and $\beta$ 'In6 inserts in the M. xanthus model. Panels $\mathrm{C}$ and $\mathrm{E}$ show the $B$. subtilis 743 RNAP-HelD complex, PDB ID 6WVK. Panels D and F show M. xanthus RNAP-HelD model. 744 RNAP is shown in grey in all panels, HelD in red, bridge helix in teal and trigger loop in yellow (see 
745 text for further details). The active site $\mathrm{Mg}^{2+}$ is shown as a small green sphere (within the dotted

746 circles). The arrows in panels $\mathrm{C}$ and $\mathrm{E}$ denote the view of the respective RNAP-HelD complex in

747 panels $\mathrm{E}$ and $\mathrm{F}$. The view in panels $\mathrm{C}$ and $\mathrm{D}$ is into the primary channel to which the clamp arm (CA)

748 of HelD binds. The view in panels $\mathrm{E}$ and $\mathrm{F}$ is into the secondary channel (dotted circle) into which the

749 secondary channel arm (SCA) is inserted. 
bioRxiv preprint doi: https://doi.org/10.1101/2021.08.18.456904; this version posted August 19, 2021. The copyright holder for this preprint (which was not certified by peer review) is the author/funder, who has granted bioRxiv a license to display the preprint in perpetuity. It is made available under aCC-BY-NC-ND 4.0 International license.

Running Title: Phylogeny of HelD

Tree scale: 0.1

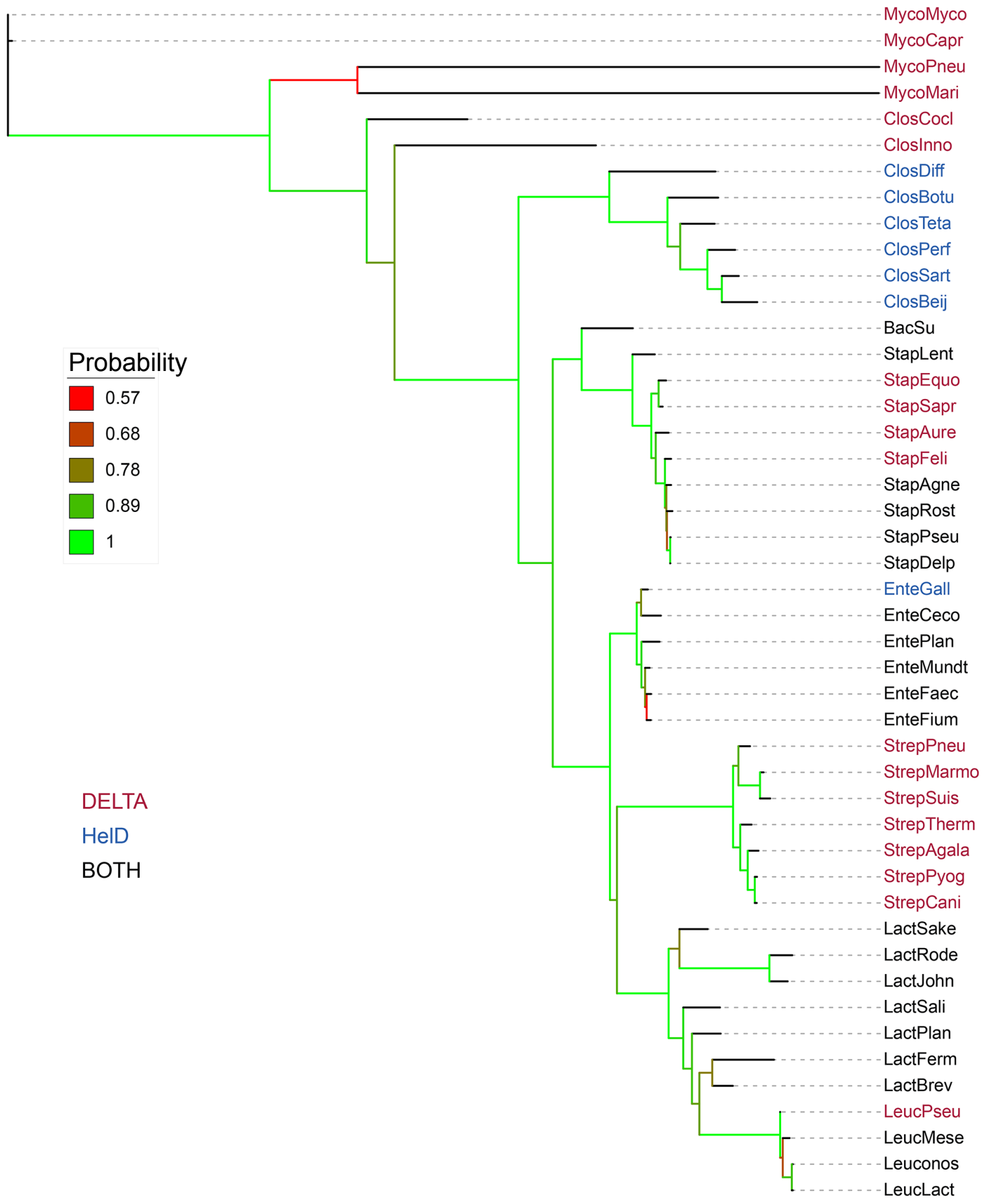

Figure 6. Phylogenetic tree of RpoB with respect to distribution of HelD and the $\delta$ subunit of RNAP.

754 Tree scale and bootstrap values are shown on the left. Organisms that contain the $\delta$ subunit (DELTA)

755 are shown in red, just HelD (blue) and both $\delta$ and HelD (black). Mycoplasma mycoides (MycoMyco),

756 Mycoplasma capricolum (MycoCapr), Mycoplasma pneumoniae (MycoPneu), Mycoplasma marinum

757 (MycoMari), Erysipelatoclostridium cocleatum (ClosCocl), Erysipelatoclostridium inoccuum

758 (ClosInno), Clostridioides difficile (ClosDiff), Clostridium botulinum (ClosBotu), Clostridium

759 perfringens (ClosPerf), Clostridium sartagoforme (ClosSart), Clostridium beijernickii (ClosBeij), 
760 Bacillus subtilis (BacSu), Staphylococcus lentus (StapLent), Staphylococcus equorum (StaphEquo)

761 Staphylococcus saprophyticus (StapSapr), Staphylococcus aureus (StapAure), Staphylococcus felis

762 (StapFeli), Staphylococcus agnetis (StapAgne), Staphylococcus rostri (Staprost), Staphylococcus

763 pseudointermidius (StapPseu), Staphylococcus delphini (StapDelp), Enterococcus gallinarum

764 (EnteGall), Enterococcus cecorum (EnteCeco), Enterococcus plantarum (EntePlan), Enterococcus

765 mundti (EnteMundt), Enterococcus faecalis (EnteFaec), Enterococcus faecium (EnteFium),

766 Streptococcus pneumoniae (StrepPneu), Streptococcus marmotae (StrepMarmo), Streptococcus suis

767 (StrepSuis), Streptococcus thermophilus (StrepTherm), Streptococcus agalactiae (StrepAgala),

768 Streptococcus pyogenes (StrepPyog), Streptococcus canis (StrepCani), Lactobacillus sakei

769 (LactSake), Lactococcus rodentium (LactRode), Lactobacillus johnsonii (LactJohn), Lactobacillus

770 salivarius (LactSali), Lactobacillus plantarum (LactPlan), Lactobacillus fermentum (LactFerm),

771 Lactobacillus brevis (LactBrev), Leuconostoc pseudomesenteroides (LeucPseu), Leuconostoc

772 mesenteroides (LeucMese), Leuconostoc sp. (Leuconos), and Leuconostoc lactis (LeucLact). 
bioRxiv preprint doi: https://doi.org/10.1101/2021.08.18.456904; this version posted August 19,2021 . The copyright holder for this preprint (which was not certified by peer review) is the author/funder, who has granted bioRxiv a license to display the preprint in perpetuity. It is made available under aCC-BY-NC-ND 4.0 International license.

Running Title: Phylogeny of HelD

A

B

B. subtilis 168

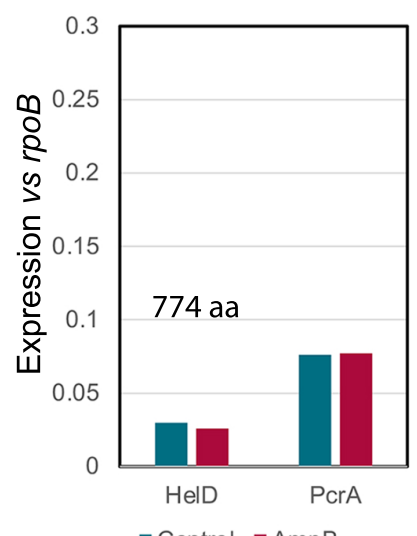

Control $\square \mathrm{AmpB}$
B. cereus F837/76

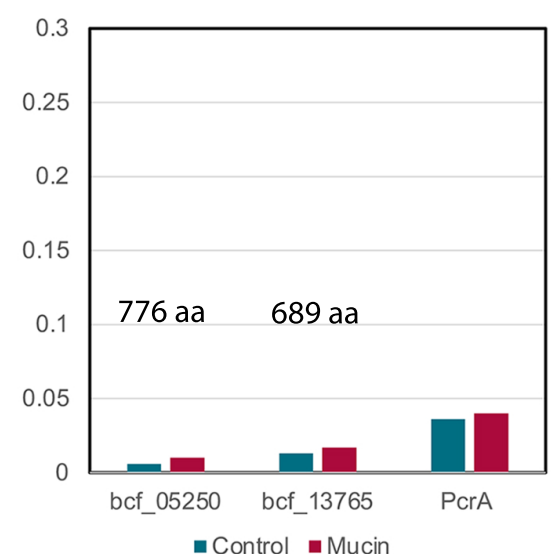

S. coelicolor A3(2)
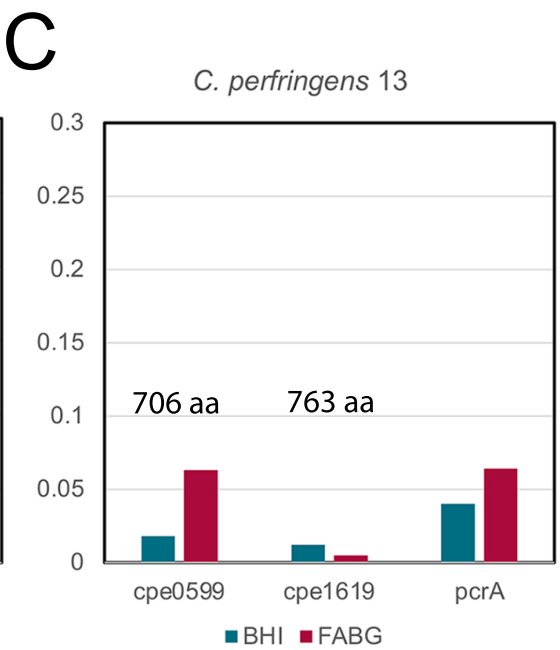

D

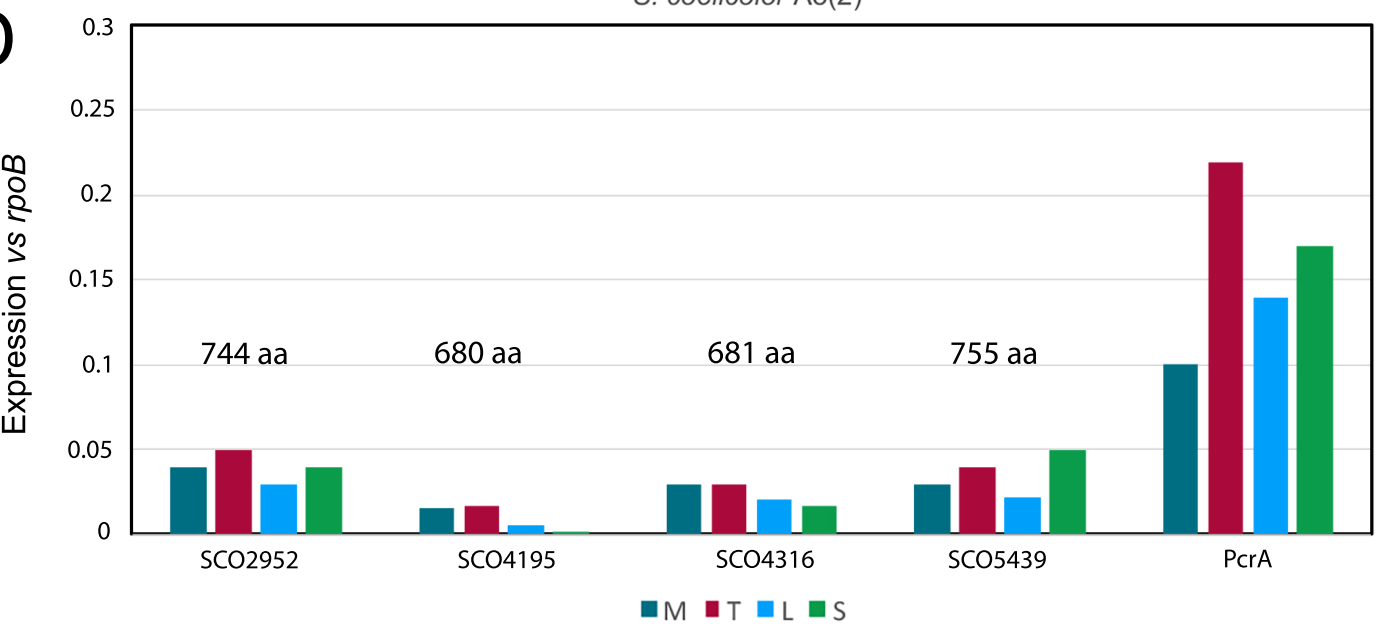

$E$

\section{$\mathrm{F}$}

G

M. smegmatis MC2-155

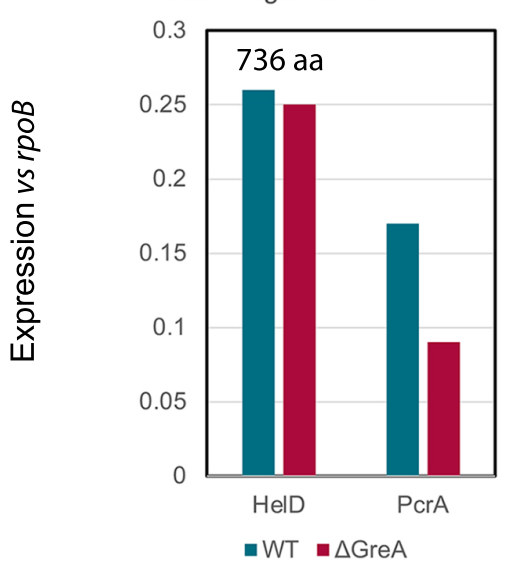

M. xanthus DK 1622

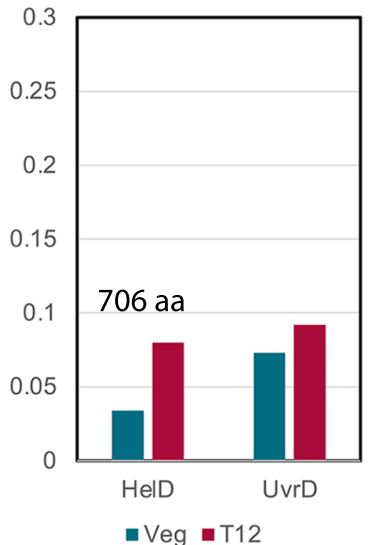

B. vulgatus ATCC 8482

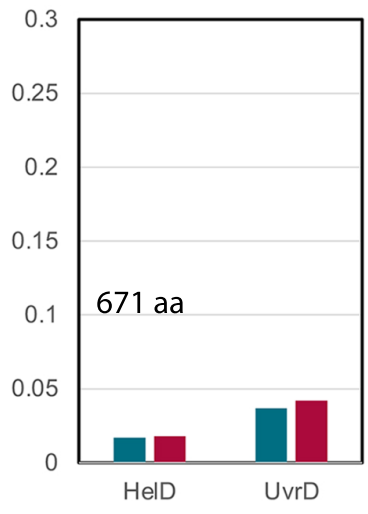

- Cont $\mathbf{a}$ Thi

Figure 7. Expression levels of HelD. The relative transcript levels of helD and $p c r A / u v r D$ compared to $r p o B$ are shown in panels A-G. Organism names are shown on the top of each plot and gene expression levels are colour coded according to the keys below the plots. The sizes of the HelD isoforms in amino acids are indicated above the corresponding column in each panel. Details of the 
779 sources of the data sets used are provided in the text. A. B. subtilis 168 data; control teal,

780 amphotericin B (AmpB) treatment red. B. B. cereus F837/76 data; control teal, mucin treatment red.

781 C. C. perfringens 13 data; growth in brain heart infusion (BHI) teal, fastidious anaerobic broth +

782 glucose (FABG) red. D. S. coelicolor A3(2) data; mid-exponential growth (M) teal, transition phase

783 (T) red, late exponential (L) blue, stationary phase (S) green. E. M. smegmatis MC2-155 data; control

784 teal, greA deletion strain $(\Delta \mathrm{GreA})$ red. F. M. xanthus DK1622 data; vegetative growth teal, 12 hours

785 after initiation of sporulation (T12) red. G. B. vulgatus ATCC 8482 data; control teal, supplemented

786 with thiamine (Thi) red. 